\author{
Jurnal Teknik Hidro \\ Vol. 11. No. 1, Februari 2018
}

\title{
KARAKTERISTIK ALIRAN PADA BANGUNAN PELIMPAH TIPE OGEE
}

\author{
Muhammad Yunus ali ${ }^{1)}$ Husaiman $^{2)}$ dan Muh. Ilham Nur ${ }^{3)}$ \\ 1) Universitas Muhammadiyah Makassar, Indonesia \\ Email : \\ 1)Universitas Muhammadiyah Makassar, Indonesia \\ Email :Husaiman09@gmail.com \\ ${ }^{2)}$ Universitas Muhammadiyah Makassar, Indonesia \\ Email :Ilham.anrecu28@gmail.com
}

\begin{abstract}
Abstrak
Pelimpah tipe ogee merupakan suatu kenaikan dari dasar suatu saluran terbuka yang berbentuk tirai luapan bawah dari bendung ambang tajam aerasi. Penelitian ini bertujuan untuk mengetahui bagaimana pengaruh bangunan pelimpah tipe ogee 1:1 terhadap karakteristik aliran pada saluran terbuka dan untuk mengetahui energi spesifik yang terjadi pada pelimpah tersebut. Penelitian ini dilakukan di laboratorium hidraulika Fakultas Teknik Univeristas Muslim Indonesia. Metode penelitian yang digunakan dalam penelitian ini adalah metode penelitian eksperimen laboratorium. Cara pengukuran dilakukan dengan metode pengukuran secara langsung menggunakan current meter dan mistar ukur. Berdasarkan pada pengukuran dan perhitungan menggunakan tiga variasi debit, dapat disimpulkan bahwa bangunan pelimpah tipe ogee 1:1 dapat mengubah aliran superkritis menjadi aliran kritis dan subkritis pada bagian hilir. Hasil penelitian menunjukkan energi spesifik bergantung pada tinggi muka air dimana semakin tinggi muka air maka semakain rendah energi spesifik yang terjadi.
\end{abstract}

Kata kunci : Karakteristik Aliran, Pelimpah Ogee, Energi Spesifik

\begin{abstract}
The ogee overflow is an increase from the bottom of an open channel which is in the form of a downflow curtain from a sharp aeration threshold. This study aims to determine how the influence of ogee 1: 1 type overflow building on the characteristics of the flow in the open channel and to find out the specific energy that occurs in the spillway. This research was conducted in Hydrolic Laboratory of Faculty of Engineering, Muslim University of Indonesia. The research method used in this research is laboratory experimental research method. The method of measurement is done by measuring method directly using current meter and measuring bar. Based on the measurements and calculations using three variations of debits, It can be concluded that ogee spillway type 1:1 can transform supercritical flow into critical and subcritical flow in the downstream. The results showed that the specific energy depends on the water level where the higher the water level then the lower the specific energy that occurs.
\end{abstract}

Keywords: Flow Characteristics, Ogee Overflow, Specific Energy 


\section{PENDAHULUAN}

Sungai merupakan penyatuan air di permukaan bumi akibat dari kelebihan curah hujan dan air tanah yang mengalir ke lembah dan membentuk alur-alur secara alamiah dengan membawa berbagai material dari tempat yang tinggi ke tempat yang rendah yang bermuara di danau atau di laut.

Sehubungan dengan pemanfaatan air untuk irigasi dan kebutuhan yang lain, seringkali dibuatlah bangunan air seperti waduk, saluran, pintu air, terjunan, bendung dan lain sebagainya guna mengatur dan mengendalikan air tersebut. Untuk menyalurkan air ke berbagai tempat guna keperluan irigasi, drainase, air bersih, dan sebagainya sering dibuat saluran dengan menggunakan saluran terbuka.

Saluran terbuka merupakan saluran dimana air mengalir dengan muka air bebas. Salah satu bangunan pelengkap yang dimiliki oleh saluran terbuka adalah bangunan pelimpah yang berfungsi menjaga saluran dari bahaya pelimpahan.

Aliran pada pelimpah menggunakan prinsip aliran kritis.
Sehingga pelimpah didesain sedemikian rupa hingga aliran yang mengalir adalah aliran kritis. Dengan aliran kritis maka debit aliran mengalir hanya tergantung dari ketinggian muka air diatas pelimpah.

Tipe pelimpah akan berpengaruh pada tinggi air dan keakuratan pengukuran debit dan kecepatan aliran. Oleh karena hal diatas, maka perlu diteliti lebih lanjut mengenai pengaruh yang ditimbulkan pelimpah tipe ogee dimensi 1:1 terhadap perubahan karakteristik aliran pada saluran terbuka.

\section{Saluran Terbuka}

Saluran terbuka adalah saluran yang mengalirkan air dengan suatu permukaan bebas. Saluran terbuka dibedakan menurut asalnya menjadi dua macam, yaitu saluran alam (natural channels) dan saluran buatan (artificials channels).

Menurut Robert J. Kodoatie dalam bukunya yang berjudul Hidrolika Terapan tahun 2002, menyatakan bahwa aliran pada saluran terbuka merupakan aliran yang mempunyai permukaan yang bebas. Permukaan yang bebas itu merupakan 
pertemuan dua fluida dengan kerapatan $\rho$ (density) yang berbeda.

Geometri atau penampang saluran (channel section) adalah tegak lurus terhadap arah aliran. Unsur-unsur geometri atau penampang pada saluran terbuka berbentuk segi empat, adalah sebagai berikut:

1) Tinggi Jagaan Saluran

$$
\mathrm{W}=0,3+0,25 \mathrm{~h}
$$

2) Luas Penampang

$$
\mathrm{A}=\mathrm{b} \times \mathrm{h}
$$

\section{Karakteristik Aliran pada Saluran} Terbuka

Karakteristik aliran pada saluran terbuka dapat dibedakan menjadi aliran kritis, subkritis, dan superkritis.
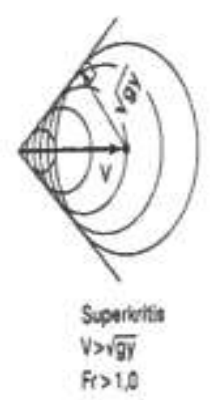
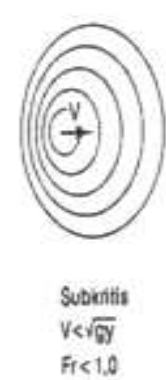

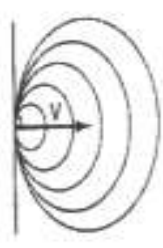

$$
\begin{aligned}
& \text { Koins } \\
& V=\sqrt{9 y} \\
& F=1,0
\end{aligned}
$$

\section{Gambar 1. Pola Penjalaran}

\section{Gelombang di Saluran Terbuka}

1) Aliran kritis apabila angka $F_{R}=1$, berarti gaya-gaya kelembamam dan gaya gravitasi seimbang.
2) Aliran subkritis apabila angka $F_{R}$ $<1$, berarti gaya gravitasi menjadi dominan dan aliran dalam keadaan aliran subkritis.

3) Aliran superkritis apabila angka $F_{R}$ $>1$, maka gaya gravitasi menjadi dominan dan aliran dalam keadaan aliran subkritis.

\section{Pelimpah Tipe Ogee}

Mercu ogee berbentuk tirai luapan bawah dari bendung ambang tajam aerasi. Oleh karena itu mercu ini tidak akan memberikan tekanan subatmosfir pada permukaan mercu sewaktu bendung mengalirkan air pada debit rencana. (Salomo Simanjuntak: 2009).

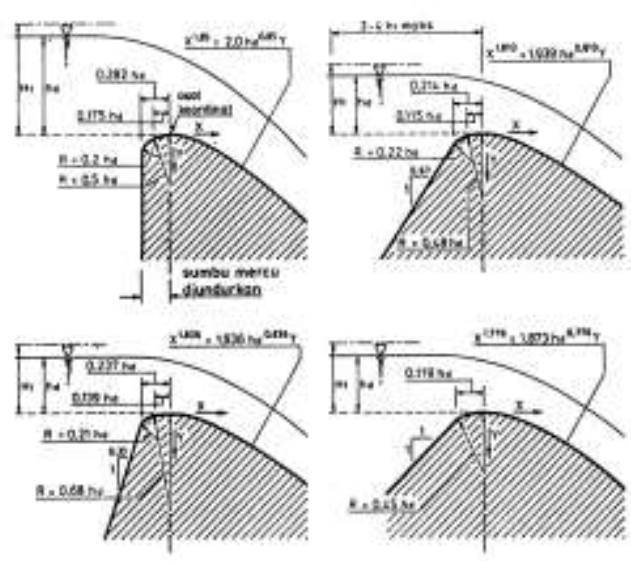

Gambar 2. Bentuk-bentuk Pelimpah Tipe Ogee

Persamaan antara tinggi energi dan debit untuk pelimpah Ogee adalah: $\mathrm{Q}=\frac{\text { volume }(\mathrm{v})}{\text { waktu rata-rata }(\mathrm{tr})}$ 
$\mathrm{Cd}=\frac{\mathrm{Q}}{\frac{2}{3} \cdot \mathrm{b} \cdot \sqrt{2 \cdot \mathrm{g}} \cdot \mathrm{H}^{1,5}}$

\section{Energi Spesifik}

Energi spesifik adalah tinggi tenaga pada sembarang tampang diukur dari dasar saluran.

Besarnya energi spesifik dapat dirumuskan sebagai berikut (Ven Te Chow, 1959 dalam Robert,J.K., 2002) :

$\mathrm{E}=\frac{v^{2}}{2 g}$

\section{METODE PENELITIAN}

Metode penelitian yang digunakan dalam penelitian ini adalah metode penelitian eksperimen laboratorium yang meliputi pengamatan atau pengukuran terhadap parameter aliran pada saluran terbuka yang menggunakan bangunan pelimpah tipe ogee dengan memperhitungkan parameter hidrolis.

Penelitian dilaksanakan di Laboratorium Hidraulika Fakultas Teknik Universitas Muslim Indonesia Makassar. Penelitian ini dilakukan selama 3 bulan, dimana bulan pertama dan kedua merupakan kajian literatur mengenai karakteristik aliran pada saluran terbuka dan melakukan desain alat kemudian dilanjutkan dengan running, selanjutnya pada bulan ketiga melakukan pengambilan dan analisis data.

Secara umum, alat dan bahan yang digunakan dalam menunjang penelitian ini terdiri dari open flume, pelimpah, stopwatch, kamera, pompa air, dan mistar ukur.

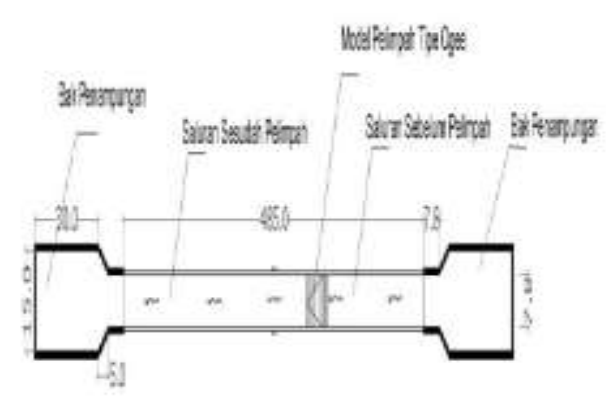

Gambar 3. Denah Alat Penelitian

\section{Gambar 4. Pelimpah Tipe Ogee}

Dimensi 1:1

\section{HASIL DAN PEMBAHASAN}

\section{Analisis Koefisien Debit (Cd)}

Cd merupakan koefisien debit pada pelimpah dan besarnya $\mathrm{Cd}$ rata-rata adalah 1,1697, sebagai contoh untuk $(\mathrm{H})=0.032 \mathrm{~m}$, volume air $(\mathrm{v})=0.01$ 
$\mathrm{m}^{3}$, dengan waktu pengaliran sebagai berikut : 6,66 det, 6,06 det, 6,44 det.

Total waktu pengaliran $=19,16$ det .

Waktu aliran rata-rata $\operatorname{tr}=\frac{19,16}{3}=6,39$ det.

$$
\begin{aligned}
\mathrm{Q} & =\frac{\text { volume }(\mathrm{v})}{\text { waktu rata-rata }(\mathrm{tr})} \\
& =\frac{0.010 \mathrm{~m}^{3}}{6,39} \\
& =0,00157 \mathrm{~m}^{3} / \mathrm{det} \\
\mathrm{Cd} & =\frac{\mathrm{Q}}{\frac{2}{3} \cdot \mathrm{b} \cdot \sqrt{2 \cdot \mathrm{g}} \cdot \mathrm{H}^{1,5}} \\
& =\frac{0,00157}{\frac{2}{3} \cdot 0,078 \cdot \sqrt{2 \cdot 9,81} \cdot 0,032^{1,5}} \\
& =1,1875 .
\end{aligned}
$$

\section{Perhitungan}

selanjutnya

diselesaikan dengan cara yang sama dan hasilnya dirangkum dalam tabel 1 dengan masing-masing volume 0,01 $\mathrm{m}^{3}$ :

Tabel 1. Perhitungan koefisien debit volume $0,01 \mathrm{~m}^{3}$

No $\quad b(m) h(m) \quad \sum_{(\text {det })}^{\sum t} \underset{\left(m^{3} / \text { det }\right)}{\mathrm{Q}} \quad \mathrm{Cd}$

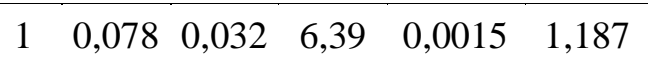

$2 \quad 0,078 \quad 0,033 \quad 6,01 \quad 0,0016 \quad 1,205$

$3 \quad 0,078 \quad 0,034 \quad 6,80 \quad 0,0014 \quad 1,018$

$4 \quad 0,078 \quad 0,037 \quad 5,23 \quad 0,0019 \quad 1,166$

$5 \quad 0,078 \quad 0,038 \quad 4,76 \quad 0,0021 \quad 1,231$

$6 \begin{array}{lllllll}6 & 0,078 & 0,039 & 4,81 & 0,0020 & 1,171\end{array}$

$\begin{array}{lllllll}7 & 0,078 & 0,04 & 4,72 & 0,0021 & 1,150\end{array}$

\begin{tabular}{lllllll}
8 & 0,078 & 0,042 & 4,31 & 0,0023 & 1,169 \\
\hline
\end{tabular}

\begin{tabular}{cccccc}
\hline 9 & 0,078 & 0,043 & 4,41 & 0,0022 & 1,104 \\
10 & 0,078 & 0,044 & 3,64 & 0,0027 & 1,292 \\
Rata-rata & 0,038 & 5,108 & 0,0020 & 1,1697 \\
\hline
\end{tabular}

Tinggi Muka Air dan Luas

\section{Penampang}

Dari hasil ketinggian air dapat dihitung luas penampang pada tiap titik didaerah hulu, dimana $b=0,078 \mathrm{~m} \mathrm{H}=0,152$ $\mathrm{m}$, luas penampang $\mathrm{A}=\mathrm{b} \times \mathrm{H}=0.078 \mathrm{x}$ $0,152=0,0119 \mathrm{~m}^{2}$.

Hasil perhitungan luas penampang pada daerah hilir, dimana $b=0,078$ $\mathrm{m} H=0,081 \mathrm{~m}$, luas penampang $\mathrm{A}=\mathrm{b}$ x $H=0,0063 \mathrm{~m}^{2}$. Perhitungan selanjutnya dihitung dengan cara yang sama.

Tabel 2. Hasil perhitungan luas penampang pada daerah hilir dengan debit $0,0015 \mathrm{~m}^{3} /$ det, $0,002 \mathrm{~m}^{3} /$ det dan $0,0025 \mathrm{~m}^{3} /$ det.

\begin{tabular}{cccccc}
\hline No & $\begin{array}{c}\mathrm{Q} \\
(\mathrm{m} 3 / \mathrm{det})\end{array}$ & $\begin{array}{c}\text { Jarak } \\
(\mathrm{m})\end{array}$ & $\mathrm{h}(\mathrm{m})$ & $\begin{array}{c}\mathrm{b} \\
(\mathrm{m})\end{array}$ & $\mathrm{A}\left(\mathrm{m}^{2}\right)$ \\
\hline 1 & & 2 & 0,08 & & 0,0063 \\
2 & & 2,75 & 0,08 & & 0,0065 \\
3 & 0,0015 & 3,4 & 0,08 & 0,078 & 0,0069 \\
4 & & 4,05 & 0,09 & & 0,0075 \\
5 & & 4,8 & 0,11 & & 0,0088 \\
1 & & 2 & 0,08 & & 0,0066 \\
2 & & 2,75 & 0,08 & & 0,0069 \\
3 & 0,0020 & 3,4 & 0,09 & 0,078 & 0,0073 \\
4 & & 4,05 & 0,10 & & 0,0079 \\
\hline
\end{tabular}




\begin{tabular}{|c|c|c|c|c|}
\hline 5 & & 4,8 & 0,11 & 0,0093 \\
\hline 1 & & 2 & 0,09 & 0,0076 \\
\hline 2 & & 2,75 & 0,10 & 0,0079 \\
\hline 3 & 0,0025 & 3,4 & $0,10 \quad 0,078$ & 0,0080 \\
\hline 4 & & 4,05 & 0,11 & 0,0087 \\
\hline 5 & & 4,8 & 0,12 & 0,0094 \\
\hline
\end{tabular}

Kecepatan Aliran, Bilangan Froude, dan Energi Spesifik

Hasil perhitungan kecepatan aliran pada daerah hulu dapat dilihat pada tabel sebagai berikut dengan debit 0,0015 $\mathrm{m}^{3} /$ det, $0,0020 \mathrm{~m}^{3} / \mathrm{det}$, dan $0,0025 \mathrm{~m}^{3} /$ det. Kecepatan didaerah hulu dilakukan lima kali percobaan tiap jarak, pada debit $0,0015 \mathrm{~m}^{3} /$ det dengan waktu pengaliran 6,21 detik, 5,41 detik, 5,59 detik, 5,93 detik, dan 5,59 detik. Total waktu pengaliran $=$ 28,73 detik.

Waktu aliran rata-rata:

$$
\begin{aligned}
\operatorname{tr} & =\frac{28,73}{5}=5,746 \text { detik. } \\
\mathrm{V} & =\frac{\text { jarak }}{\text { waktu rata-rata }(\mathrm{tr})}=\frac{0,80}{5,746} \\
& =0,1392 \mathrm{~m} / \text { det. }
\end{aligned}
$$

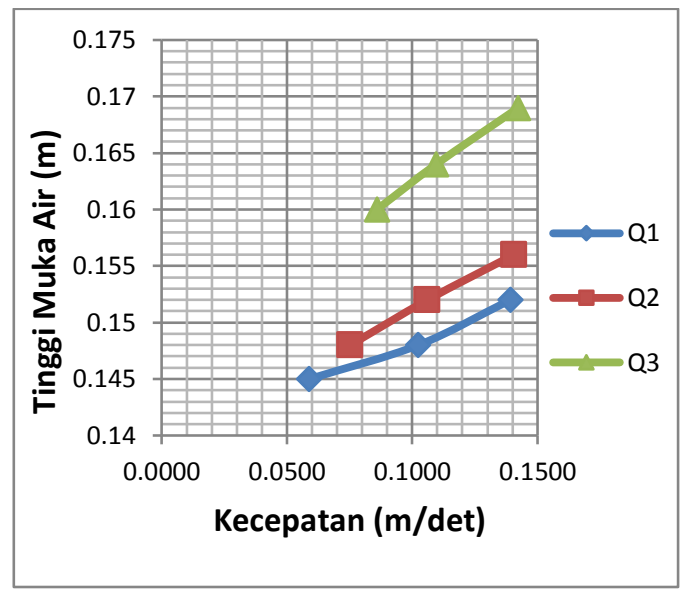

Gambar 5. Hubungan antara kecepatan dan tinggi muka air pada daerah hulu

Hasil perhitungan bilangan froude pada debit $0,0015 \mathrm{~m}^{3} / \mathrm{det}$, $0,0020 \mathrm{~m}^{3} /$ det, dan $0,0025 \mathrm{~m}^{3} /$ det di daerah hulu dapat dilihat pada tabel berikut, pada debit $0,0015 \mathrm{~m}^{3} /$ det $\mathrm{V}=$ $0,1479 \mathrm{~m} / \mathrm{det}, \mathrm{g}=9,81 \mathrm{~m}^{2} / \mathrm{det}, \mathrm{h}=$ $0,152 \mathrm{~m}$ dan dijabarkan sebagai berikut: $\mathrm{Fr}=\frac{0,1479}{\sqrt{9,81 \cdot 0,152}}=0,1211$.

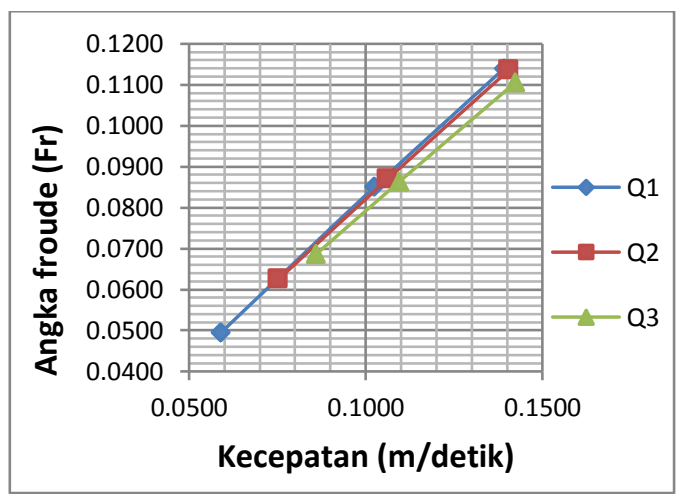

Gambar 6. Hubungan antara kecepatan dan bilangan froude pada bagian hulu

Hasil perhitungan energi spesifik pada debit $0,0015 \mathrm{~m}^{3} /$ det, 
$0,0020 \mathrm{~m}^{3} /$ det, dan $0,0025 \mathrm{~m}^{3} /$ det di daerah hulu dapat dilihat pada tabel berikut.

$$
\text { Es }=0,152+\left(\frac{0,1392^{2}}{2 \cdot 9,81}\right)=0,1530 \mathrm{~m} .
$$

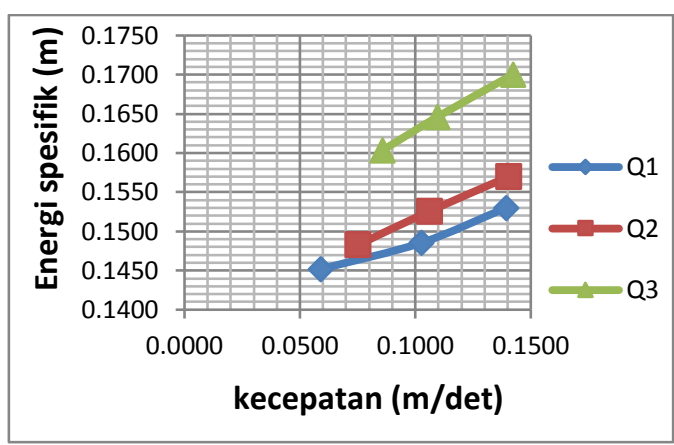

Gambar 7. Hubungan antara kecepatan dan energi spesifik pada daerah hulu.

Perhitungan kecepatan pada bangunan dengan debit $0,0015 \mathrm{~m}^{3} / \mathrm{det}$, $0,0020 \mathrm{~m}^{3} /$ det, dan $0,0025 \mathrm{~m}^{3} /$ det dirangkum pada tabel 16, dimana Q $=0,0015 \mathrm{~m}^{3} /$ det $, \mathrm{b}=0,078 \mathrm{~m}, \mathrm{~g}=9,81$ $\mathrm{m}^{2} /$ det dan dijabarkan sebagai berikut: $\mathrm{q}=\frac{\mathrm{Q}}{\mathrm{b}}=\frac{0,0015}{0,078}=0,0192 \mathrm{~m}^{3} / \mathrm{det} / \mathrm{m}$ $\mathrm{h}_{\mathrm{c}}=\sqrt[3]{\frac{\mathrm{q}^{2}}{\mathrm{~g}}}=\sqrt[3]{\frac{0,0192^{2}}{9,81}}=0,033 \mathrm{~m}$ $\mathrm{Vc}=\sqrt{\mathrm{g} \cdot \mathrm{yc}}=\sqrt{9,81 \times 0,033}=0,5735$ $\mathrm{m} / \mathrm{det}$

Perhitungan bilangan froude pada bangunan pada debit 0,0015 $\mathrm{m} 3 /$ det, $0,0020 \mathrm{~m} 3 /$ det, dan 0,0025 $\mathrm{m} 3 /$ det dirangkum pada tabel 23, dimana $\mathrm{Q}=0,0015 \mathrm{~m} 3 / \mathrm{det}, \mathrm{b}=$
$0,078 \mathrm{~m}, \mathrm{~g}=9,81 \mathrm{~m} 2 / \mathrm{det}$ dan dijabarkan sebagai berikut:

$\mathrm{Fr}=\frac{\mathrm{V}}{\sqrt{\mathrm{g} \cdot \Delta \mathrm{y}}}=\frac{0,5735}{\sqrt{9,81 \cdot 0,033}}=1$

Perhitungan energi spesifik pada bangunan, dimana $\mathrm{Q}=0,0015$ $\mathrm{m}^{3} /$ det, yc $=0,0335 \mathrm{~m}, \mathrm{Vc}=0,1479$ $\mathrm{m} /$ det, $\mathrm{g}=9,81$ dan dijabarkan sebagai berikut :

Es $=0,0335+\left(\frac{0,5735^{2}}{2 \cdot 9,81}\right)=0,0503 \mathrm{~m}$

Perhitungan selanjutnya dihitung dengan cara yang sama.

Perhitungan kecepatan pada daerah setelah bangunan dengan debit $0,0015 \mathrm{~m}^{3} / \mathrm{det}, \quad 0,0020 \mathrm{~m}^{3} / \mathrm{det}$, dan $0,0025 \mathrm{~m}^{3} /$ det dirangkum pada tabel 17,18, dan 19 dimana $\mathrm{Q}=0,0015$ $\mathrm{m}^{3} /$ det, $\mathrm{b}=0,078 \mathrm{~m}, \mathrm{~g}=9,81 \mathrm{~m}^{2} /$ det , y2 =0,081 ( Tinggi muka air sebelum melewati bangunan) dan dijabarkan sebagai berikut:

$\Delta \mathrm{y}=\mathrm{y} 2-\mathrm{y} 1=0,081-0,045=0,0360 \mathrm{~m}$ $\mathrm{V}=\sqrt{2 \cdot \mathrm{g} \cdot \Delta \mathrm{y}}=\sqrt{2 \cdot 9,81 \cdot 0,0360}=0,8404$ $\mathrm{m} / \mathrm{det}$

Perhitungan bilangan froude pada daerah setelah bangunan pelimpah pada debit 0,0015 $\mathrm{m}^{3} / \mathrm{det}, \quad 0,0020$ $\mathrm{m}^{3} /$ det, dan $0,0025 \mathrm{~m}^{3} /$ det dirangkum pada tabel 24, dimana $\mathrm{Q}=0,0015$ $\mathrm{m}^{3} /$ det, $\mathrm{b}=0,078 \mathrm{~m}, \mathrm{~g}=9,81 \mathrm{~m}^{2} /$ det $\mathrm{V}$ 
$=0,8404 \mathrm{~m} / \mathrm{det}, \Delta \mathrm{y}=0,0550 \mathrm{~m}$ dan dijabarkan sebagai berikut :

$\mathrm{Fr}=\frac{\mathrm{V}}{\sqrt{\mathrm{g} \cdot \Delta \mathrm{y}}}=\frac{0,8404}{\sqrt{9,81 \cdot 0,0360}}=1,2649$

Perhitungan energi spesifik pada daerah setelah bangunan pada debit $0,0015 \mathrm{~m}^{3} /$ det, $0,0020 \mathrm{~m}^{3} /$ det, $0,0025 \mathrm{~m}^{3} /$ det. Pada debit 0,0015 $\mathrm{m}^{3} /$ det, dimana $\Delta \mathrm{y}=0,0360 \mathrm{~m}, \mathrm{~V}=$ $0,8404 \mathrm{~m} /$ det, $\mathrm{g}=9,81$ dan dijabarkan sebagai berikut:

Es $=0,0360+\left(\frac{0,8404^{2}}{2 \cdot 9,81}\right)=0,072 \mathrm{~m}$

Perhitungan selanjutnya dihitung dengan cara yang sama dan dirangkum pada tabel.

Hasil perhitungan kecepatan pada daerah hilir pada debit 0,0015 $\mathrm{m}^{3} /$ det, $0,0020 \mathrm{~m}^{3} /$ det, $0,0025 \mathrm{~m}^{3} /$ det, dicari menggunakan current meter dan dirangkum pada tabel.

Hasil perhitungan bilangan froude pada daerah hilir pada debit $0,0015 \mathrm{~m}^{3} /$ det, $0,0020 \mathrm{~m}^{3} /$ det, 0,0025 $\mathrm{m}^{3} /$ det, pada debit $0,0015 \mathrm{~m}^{3} /$ det dimana $\mathrm{V}=0,30 \mathrm{~m}, \mathrm{~g}=9,81, \mathrm{y}=0,081$ $\mathrm{m}$ dan dijabarkan sebagai berikut : $\mathrm{Fr}=\frac{\mathrm{V}}{\sqrt{\mathrm{g} \cdot \mathrm{y}}}=\frac{0,30}{\sqrt{9,81 \cdot 0,081}}=0,3365$
Perhitungan selanjutnya dikerjakan dengan cara yang sama dan dirangkum pada tabel.

Apabila kecepatannya besar maka energy spesifiknya akan tinggi. Dapat dilihat bahwa energy spesifik yang paling tinggi terdapat pada debit (Q3=0.0025 m/det).

Hasil perhitungan energi spesifik pada daerah hilir pada debit $0,0015 \mathrm{~m}^{3} /$ det, $0,0020 \mathrm{~m}^{3} / \mathrm{det}, 0,0025$ $\mathrm{m}^{3} /$ det, pada debit $0,0015 \mathrm{~m}^{3} /$ det dimana $\mathrm{h}=0,081 \mathrm{~m}, \mathrm{~V}=0,30 \mathrm{~m} / \mathrm{det}, \mathrm{g}$ $=9,81$ dan dijabarkan sebagai berikut:

Es $=0,081+\left(\frac{0,30^{2}}{2.9,81}\right)=0,0856 \mathrm{~m}$

Perhitungan selanjutnya diselesaikan dengan cara yang sama dan hasilnya dirangkum dalam tabel 3.

Tabel 3. Hasil perhitungan kecepatan aliran, bilangan froude, dan energi spesifik pada daerah hilir dengan debit $0,0015 \mathrm{~m}^{3} / \mathrm{det}, 0,0020 \mathrm{~m}^{3} / \mathrm{det}, 0,0025$ $\mathrm{m}^{3} / \mathrm{det}$

\begin{tabular}{lccccc}
\hline No & $\begin{array}{c}\mathrm{Q} \\
(\mathrm{m} 3 / \mathrm{det})\end{array}$ & $\mathrm{h}(\mathrm{m})$ & $\begin{array}{c}\mathrm{V} \\
(\mathrm{m} / \mathrm{det})\end{array}$ & Fr & Es \\
\hline 1 & & 0,08 & 0,30 & 0,336 & 0,085 \\
2 & & 0,08 & 0,30 & 0,332 & 0,087 \\
3 & 0,0015 & 0,08 & 0,30 & 0,322 & 0,092 \\
4 & & 0,09 & 0,20 & 0,206 & 0,098 \\
5 & & 0,11 & 0,20 & 0,190 & 0,115 \\
1 & & 0,08 & 0,30 & 0,328 & 0,089 \\
2 & 0,002 & 0,08 & 0,30 & 0,322 & 0,092 \\
\hline
\end{tabular}




\begin{tabular}{|c|c|c|c|c|}
\hline 3 & & 0,09 & 0,30 & $0,314 \quad 0,097$ \\
\hline 4 & & 0,10 & 0,20 & $0,200 \quad 0,103$ \\
\hline 5 & & 0,11 & 0,20 & $0,1850,121$ \\
\hline 1 & & 0,09 & 0,40 & $0,410 \quad 0,105$ \\
\hline 2 & & 0,10 & 0,40 & $0,401 \quad 0,109$ \\
\hline 3 & 0,0025 & 0,10 & 0,40 & $0,3990,110$ \\
\hline 4 & & 0,11 & 0,30 & $0,2860,116$ \\
\hline 5 & & 0,12 & 0,30 & $0,275 \quad 0,125$ \\
\hline
\end{tabular}

Kehilangan Energi

Kehilangan energi spesifik pada daerah hulu dan hilir pada debit 0,0015 $\mathrm{m}^{3} /$ det dititik tinjauan dengan jarak 0,705 m sebelum pelimpah dan jarak $2.00 \mathrm{~m}$ pada daerah hilir adalah sebagai berikut :

$\Delta \mathrm{E}=0,1516-0,0856=0,066 \mathrm{~m}$

Kehilangan energi spesifik pada daerah hulu dan hilir pada debit 0,002 $\mathrm{m}^{3} /$ det dititik tinjauan dengan jarak 0,70 m sebelum pelimpah dan jarak $2.00 \mathrm{~m}$ pada daerah hilir adalah sebagai berikut :

$\Delta \mathrm{E}=0,1567-0,0896=0,0671 \mathrm{~m}$

Kehilangan energi spesifik pada daerah hulu dan hilir pada debit $0,0025 \mathrm{~m}^{3} /$ det dititik tinjauan dengan jarak 0,695 m sebelum pelimpah dan jarak $2.00 \mathrm{~m}$ pada daerah hilir adalah sebagai berikut :

$\Delta \mathrm{E}=0,1694-0,1052=0,0642 \mathrm{~m}$
Kehilangan energi spesifik pada daerah setelah bangunan sebagai contoh pada debit $0,0015 \mathrm{~m}^{3} / \mathrm{det}$ dengan $\mathrm{y} 1=0,045 \mathrm{~m}, \mathrm{y} 2=0,081 \mathrm{~m}$ dihitung dan dijabarkan sbb :

$$
\begin{aligned}
\Delta y & =y 2-y 1=0,081-0,045 \\
& =0,0360 \mathrm{~m} .
\end{aligned}
$$$$
\Delta \mathrm{E}=\frac{(\mathrm{y} 2-\mathrm{y} 1)^{3}}{4 \mathrm{xy} 2 \mathrm{xy} 1}=\frac{0.0360}{4 \mathrm{x} 0,81 \times 0,045}
$$$$
=0.0018 \mathrm{~m} \text {. }
$$

\section{Debit}

Dari penelitian ini digunakan 3 variasi debit yaitu $0,0015 \mathrm{~m}^{3} /$ det, $0,0020 \mathrm{~m}^{3} /$ det, $0,0025 \mathrm{~m}^{3} /$ det.

\section{Kecepatan Aliran}

Dari hasil perhitungan pada tabel diketahui bahwa semakin tinggi muka air maka semakin besar kecepatan yang terjadi.

Dari hasil perhitungan pada tabel 18, 19 dan 20 diketahui bahwa semakin tinggi muka air maka semakin rendah kecepatan yang terjadi.

Dari hasil perhitungan pada tabel 21 dengan menggunakan current meter dan dari hasil perhitungan kecepatan paling besar terjadi pada saat setelah air melewati bangunan pelimpah.

\section{Bilangan Froude}


Dari hasil perhitungan diperoleh bilangan Froude yang cukup bervariasi dikarenakan pengambilan data dilakukan pada jarak tertentu tiap titiknya.

\section{Energi Spesifik}

Dari hasil perhitungan energi spesifik pada daerah hulu diketahui bahwa semakin besar kecepatan maka semakin besar pula energi spesifik yang terjadi. Pada daerah hilir dapat diketahui bahwa semakin besar kecepatan maka semakin kecil energi yang terjadi.

\section{Kehilangan Energi}

Dari hasil perhitungan kehilangan energi dapat dilihat pada daerah hulu dan hilir dimana semakin tinggi debit maka kehilangan energi semakin rendah.

\section{PENUTUP}

\section{Kesimpulan}

Adapun kesimpulan pada penelitian pengaruh bangunan pelimpah tipe ogee 1:1 terhadap karasteristik aliran pada saluran terbuka adalah:

1) Pengaruh bangunan pelimpah tipe ogee 1:1 dapat mengubah aliran superkritis menjadi aliran kritis dan subkritis pada bagian hilir.
2) Energi spesifik bergantung pada tinggi muka air dimana semakin tinggi muka air maka semakain rendah energi spesifik yang terjadi.

\section{Saran}

Disadari bahwa penelitian ini jauh dari kesempurnaan, sehingga penelitian ini masih perlu dikaji untuk beberapa kondisi berikut.

1) Pengukuran kecepatan aliran dan tinggi muka air agar dilakukan dengan teliti lagi agar mendapatkan hasil yang lebih akurat.

2) Untuk penyempurnaan dan pengembangan, penelitian selanjutnya disarankan untuk memakai kolam olakan dan menggunakan saluran yang lebih lebar lagi.

\section{DAFTAR PUSTAKA}

Canonica, Lucio. 2013. Memahami Hidraulika Edisi Revisi. CV Angkasa, Bandung.

Chow, VT. 1985. Terjemahan Suyatman, Sugiharto, dan Rosalina. Hidrolika Saluran Terbuka. Penerbit Erlangga, Jakarta.

Direktur Jenderal Pengairan. 1986. Kriteria Perencanaan. Direktorat Jenderal Pengairan, Jakarta. 
Ernandi, Rhidho. 2012. Aliran Fluida. 17 Mei 2012. Online dari http://Ridho-Ernandi/aliranfluida.html. Diakses pada tanggal 9 Maret 2018.

Gandakoesoema. 1983. Hidrolika. Penerbit Sumur Bandung, Bandung.

Kodoatie, Robert J. 2002. Hidrolika Terapan Edisi Revisi. Penerbit Andi, Yogyakarta.

Simanjuntak, Salomo. 2009. Analisa Mercu Bendung Daerah Irigasi Namurambe. Laporan Penelitian, Medan: Lembaga Penelitian Universitas HKBP Nommensen.

SNI 8137. 2015. Pengukuran Debit pada Saluran Terbuka Menggunakan Bangunan Ukur Tipe Pelimpah Atas. Badan Standar Nasional, Jakarta.

Triatmodjo, Bambang. 1993. Hidrolika II. Beta Offset, Yogyakarta.

Yudah, G, S. 2014. Analisa Kapasitas Sungai dalam Mengendalikan Banjir dengan Integrasi Antara Metode Rasiona dengan Program WIN-TR (Studi Kasus Daerah Aliran Sungai Air Bengkulu). Skrispsi, Bengkulu: Fakultas Teknik Jurusan Sipil Universitas Bengkulu.

Yuni, Cahya. S. D. 2012. Kajian Perubahan Pola Gerusan Pada Tikungan Sungai Akibat Penambahan Debit. Skripsi, Makassar: Fakultas Teknik Jurusan Sipil Universitas Hasanuddin. 